\title{
Hydrogeological Investigation and Parameter Analysis of Floodplain Area in the Reaches of the Yangtze River
}

\author{
Xia Pengju ${ }^{1}$, Zhang Lei $^{1}$, Liang Yuqiang ${ }^{1}$, Li Yandong ${ }^{1}$, Shao Hailong ${ }^{1}$, Song Xiangdong ${ }^{2 *}$ \\ ${ }^{1}$ CCCC Tunnel Engineering Co., Ltd., Beijing, 100000 \\ ${ }^{2}$ Shanghai Changkai Geotechnical Engineering Co., Ltd., 200093, China
}

\begin{abstract}
The binary structure of the floodplain in the reaches of the Yangtze River is obvious and has unique hydrogeological features. In this paper, the hydrogeological survey of the floodplain area is carried out. It is found that the permeability coefficient of the floodplain area is gradually increasing from top to down, and is larger than that of the similar layer in other areas. The horizontal and vertical permeability coefficients are not much different. This hydrological survey results of this paper provide a certain reference for similar dewatering projects in the floodplain area of the lower reaches of the Yangtze River.
\end{abstract}

\section{Introduction}

The lower reaches of the Yangtze River have a wide river surface and a slow flow velocity. A large amount of gravel carried from the upstream gradually deposits downstream. Due to the long-term lateral migration of the Yangtze River and the sedimentation of the tidal zone above the tidal zone, the floodplain of the lower reaches of the Yangtze River is widely distributed.

The floodplain sediments are quite different from other types of sediments. The most prominent feature is that the binary structure is obvious. The top-down particles are obviously from fine to coarse, and the upper part is composed of finer river floodplain composition (mainly fine sand and clay), the lower part consists of coarser riverbed alluvial deposits (mainly coarse sand and gravel). This dual structure causes the hydrogeological characteristics of the aquifers in the floodplain area to be different from other areas, and it is not possible to just apply hydrogeological experience in other areas.

At present, there are a large number of buildings in the floodplain area of the middle and lower reaches of the Yangtze River. The deep and large foundation pits are increasing, and the groundwater problems are becoming more and more complicated. Therefore, special hydrogeological surveys are needed to determine the water level geological parameters of the floodplain area in order to provide a reasonable basis for dewatering engineering design and construction.

Based on the engineering geological and hydrogeological survey results of Nanjing and Yangzhou, this paper analyses the hydrogeological conditions of the floodplain area in the lower reaches of the Yangtze River, and provides a reference for similar dewatering projects in the floodplain area of the lower reaches of the Yangtze River.

\footnotetext{
*Corresponding author's e-mail: songxiangdongsd@163.com
}

\section{Geological conditions}

According to a geotechnical investigation report of a crossing-river tunnel project in Nanjing and a foundation pit project of a steel plant in Yangzhou, the geological conditions of the Yangtze River floodplain in these two places are as follows:

The Yangtze River floodplain in Nanjing is located between Pukou, Liuhe and Qixia District, Gulou District. It is distributed along the northeast--western direction along the Yangtze River. The shallow aquifer is mainly composed of (1) layer, (2) 1 layer of cohesive soil and (2)2 silt soil, and partially contains a silt and silty soil layer. Its permeability and water-richness are low with a poor water content. The (micro) confined aquifer is mainly sandy soil, which is directly connected to the Yangtze River channel area. It appears a distinct binary structure, coarse and fine. The upper section is (2) 3 (2) 6 layers of silt, fine sand, the lower section is (4) layer, mainly medium coarse sand, gravel sand, round gravel, partially fine sand. The bedrock fissure water mainly exists in the underlying bedrock (Cretaceous mudstone, argillaceous sandstone), which has a large depth and has no effect on the project. The groundwater level is generally $1 \sim 3 \mathrm{~m}$ beneath the ground.

The Yangtze River floodplain in Yangzhou area mainly occurs in the (1) silt layer and (2) silty clay layer, and the (micro) confined aquifer exists in (2) 1 silt clay layer, (3)s of silt-clay layer, (4)silt layer, 5 fine sand layer, 7 fine sand layer, strong water-rich, accept lateral replenishment. The 7 layers of deep particles gradually thicken. The buried depth of the groundwater level is generally $1-3 \mathrm{~m}$.

Although the stratigraphic number are different in the two strata, the stratum structure is basically the same. The phreatic layer has a shallow depth. The saturated clay layer and the silty clay layer are mainly distributed, and the 
permeability coefficient is small. They could be thought as the relative impervious layer with a thickness of 10$15 \mathrm{~m}$. The intermediate riverbed phase and the floodplain phase are interbedded with each other, mainly composed of silt and silty clay, which is a micro-confined aquifer with a thickness of $20-30 \mathrm{~m}$. The lower gravel layer is the main aquifer, and the lithology is mainly the sediment of the riverbed facies, silt, fine sand and so on.

Since the two projects are close to the Yangtze River (less than 500 meters away from the Yangtze River), the groundwater level is evidently affected by the water level of the Yangtze River, of which daily fluctuation is more than 1 meter. Under the influence of Yangtze River, the fluctuation of groundwater level can reach $30 \mathrm{~cm}$ in one day. This brings certain difficulties to the data analyse of hydrogeological surveys. It is necessary to eliminate the influence of surface water fluctuations in order to analyse and calculate the survey data.

\section{Hydrogeological test wells arrangement}

In order to explore the differences between the upper and lower hydrogeological parameters of the floodplain, the test wells were arranged in the main aquifers of the two places. The layout of the test wells in a cross-river tunnel project in Nanjing is shown in Figure 1. The well structure layout is shown in Table 1. The layout of the test wells in a project in Yangzhou is shown in Figure 2. The well structure is shown in Table 2.

Table 1. Structural parameters of the test well

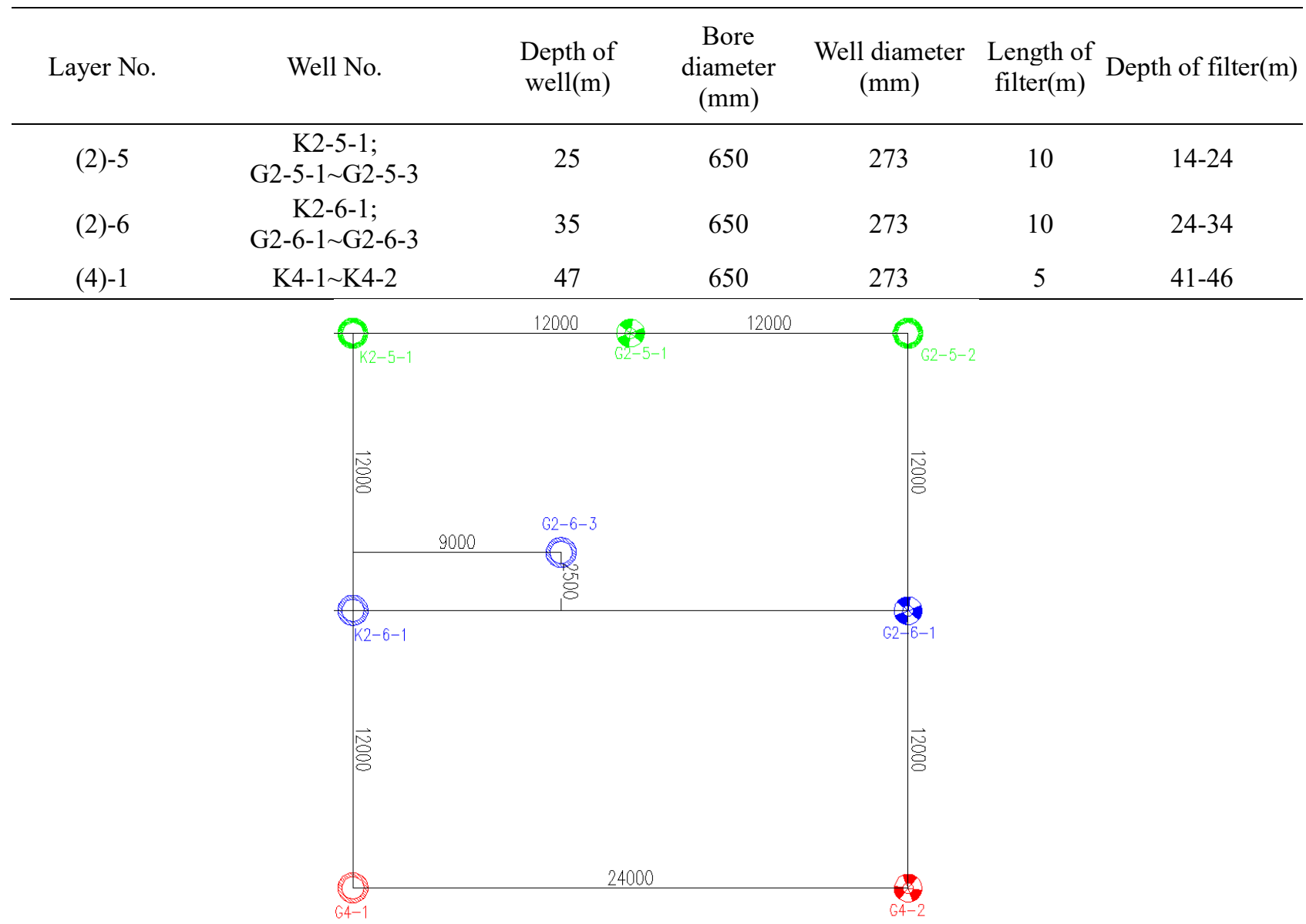

Figure.1 Diagram of recharge test well location ( $\mathrm{K}$ - for recharge well, $\mathrm{G}$ - for observation well)

Table 2. Structural parameters of the test well in Yangzhou

\begin{tabular}{|c|c|c|c|c|c|c|}
\hline Layer No. & Well No. & $\begin{array}{l}\text { Depth of } \\
\text { well(m) }\end{array}$ & $\begin{array}{c}\text { Bore } \\
\text { diameter } \\
(\mathrm{mm})\end{array}$ & $\begin{array}{l}\text { Well diameter } \\
\qquad(\mathrm{mm})\end{array}$ & $\begin{array}{l}\text { Length of } \\
\text { filter(m) }\end{array}$ & $\begin{array}{l}\text { Depth of } \\
\text { filter(m) }\end{array}$ \\
\hline (2) 1 (5) & $\mathrm{C} 5-1$ & 43 & 700 & 325 & 31 & $11-42$ \\
\hline (2) $\sim$ (5) & G5-1, G5-2 & 43 & 650 & 273 & 28 & $11-33,36-42$ \\
\hline (7) & $\mathrm{C} 7-1, \quad \mathrm{C} 7-2$ & 57 & 700 & 325 & 8 & 48-56 \\
\hline (7) & G7-1, G7-2 & 57 & 650 & 273 & 8 & $48-56$ \\
\hline
\end{tabular}




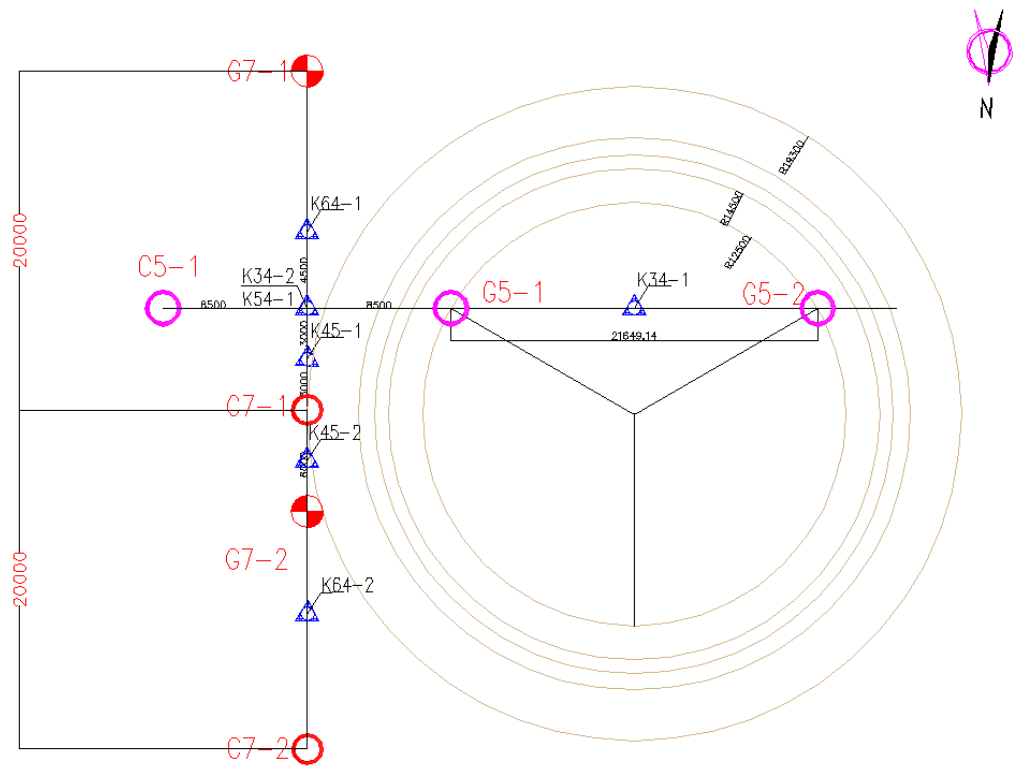

Figure.2 Diagram of recharge test well location ( $\mathrm{K}$ - for recharge well, $\mathrm{G}$ - for observation well)

\section{Hydrogeological survey results}

According to the hydrogeological survey results, the maximum outflow of $25 \mathrm{~m}$ deep well in the (2) 5 fine sand layer in Nanjing is about $174 \mathrm{~m}^{3} / \mathrm{h}$; the maximum outflow of $35 \mathrm{~m}$ deep well in the (2)6 fine sand layer is about $224 \mathrm{~m}^{3} / \mathrm{h}$; the maximum outflow of $47 \mathrm{~m}$ deep well in the lower part of the (2)6 fine sand layer is about $308 \mathrm{~m} 3 / \mathrm{h}$. In the Yangzhou area, the maximum outflow of in the $43 \mathrm{~m}$ deep well in the (2) (5) silt-sand layer is about $266 \mathrm{~m}^{3} / \mathrm{h}$, and the maximum outflow of $57 \mathrm{~m}$ deep well in (7) fine sand layer is about $460 \mathrm{~m}^{3} / \mathrm{h}$. It can be seen that the deep underground aquifer in the floodplain area has rich water yield property and abundant water supply. Therefore, a large pump and a large-diameter drainage pipe should be equipped according to the depth of the well to meet the needs of construction pumping and drainage.

Hydrogeological parameters are shown in the Tab.3.

Table 3. Hydrogeological parameters in Nanjing and Yangzhou

\begin{tabular}{ccccc}
\hline \multirow{2}{*}{ Area } & Layer No. & $\begin{array}{c}\text { Horizontal permeability } \\
\text { coefficient(m/d) }\end{array}$ & $\begin{array}{c}\text { Vertical permeability } \\
\text { coefficient }\end{array}(\mathrm{m} / \mathrm{d})$ & $\begin{array}{c}\text { Water storage } \\
\text { coefficient }\end{array}$ \\
\hline \multirow{3}{*}{ Nanjing } & $(2) 5$ & 15 & 12 & $1.0 \mathrm{E}-03$ \\
& $(2) 6$ & 50 & 35 & $1.2 \mathrm{E}-03$ \\
Yangzhou & $(2) 6-(4) 1$ & 90 & 70 & $1.0 \mathrm{E}-03$ \\
& $(2)(5)$ & 30 & 32 & $0.8 \mathrm{E}-03$ \\
& $(7)$ & 42 & & $1.2 \mathrm{E}-03$ \\
\hline
\end{tabular}

It can be seen from the above table that the permeability coefficient of the floodplain strata near Yangtze River is quite large, and it increases accordingly with the increase of the depth. Compared with the same type of soil in other areas, the permeability coefficient of the soil in the floodplain area is generally larger, which may be caused by the site approaching the Yangtze River and the high water supply. The ratio of the horizontal permeability coefficient to the vertical permeability coefficient of most strata is about 1.2:1 1.5:1 without much difference. It can be seen that the self-weight pressure of the upper soil has not crushed the deep sand gravel particles nor fully cemented consolidation. The ratio of the horizontal and vertical permeability coefficients of the (2) (5) layers in Yangzhou area is $10: 1$. This is related to the thin layers of clay revealed by geotechnical investigation
After the test well is stopped, the water level recovers very quickly. It can recover $15 \%$ in just 1 minute and $60 \%$ in 10 minutes. Therefore, in the construction of the foundation pit near Yangtze River floodplain, sufficient safety margin must be ensured, and the reserve power (generator) must be equipped and automatically switched.

\section{Conclusions}

From the top to the bottom, the floodplain area near Yangtze River is the river floodplain, and the riverbed phase, transiting from the silty clay layer to the fine sand layer and then to the gravel layer. The sand layer in the floodplain area is thicker, and its obvious upper and lower binary structure causes the soil layer permeability coefficient to increase with the increase of depth. Compared with the same type of soil in other areas, the permeability coefficient of the soil in the floodplain area is generally larger. Due to the large supply and large 
permeability coefficient, the floodplain area recovered quickly after stopping pumping.

Based on these characteristics of the aquifer in the floodplain area, in the design and construction of the dewatering project, it is necessary to fully understand the water outflow and to pay attention to the lateral and vertical ground water supply, ensuring sufficient safety margin, and equipping with appropriate water pump and drainage pipe. And the power supply and the continuous operation of the pump is also needed to ensure the safe construction of the foundation pit.

\section{References}

1. Liu Shikai. Physical and mechanical properties and engineering geological evaluation of modern river floodplain in the middle and lower reaches of the Yangtze River[J]. Journal of Engineering Geology, 2001, 9(2).

2. Zhang Linghua, Zhang Zhenke, Fu Yuexin, et al. Grain size characteristics of floodplain in Zhenjiang section of Nanjing in the lower reaches of the Yangtze River[J]. GEOGRAPHICAL SCIENCE, 2015, 35(9).

3. Song Xiangdong et al. Analysis of recharge test in floodplain area near Yangtze River in Nanjing[C]. IOP Conf. Ser.: Earth Environ. Sci. 2019 ,304 022090

4. Zhou Zhifang, Tang Ruiliang, Wang Bin. Determination of hydrogeological parameters of aquifer based on pumping test data $[\mathrm{J}]$. Journal of Hohai University, 1999, 27(3): 5-8.

5. Yao Tianqiang. Foundation pit dewatering manual [M]. Beijing: China Building Industry Press, 2006

6. Wu Jichun. Groundwater Dynamics [M]. Beijing: Geological Publishing House, 2009. 